\author{
Marquette University \\ e-Publications@Marquette
}

\title{
8-2011
}

\section{Resonant Microcantilevers for the Determination of the Loss Modulus of Thin Polymer Films}

\author{
Cedric Ayela \\ Université de Bordeaux \\ Stephen M. Heinrich \\ Marquette University, stephen.heinrich@marquette.edu \\ Fabien Josse \\ Marquette University, fabien.josse@marquette.edu \\ Isabelle Dufour \\ Université de Bordeaux
}

Follow this and additional works at: https://epublications.marquette.edu/civengin_fac

Part of the Civil and Environmental Engineering Commons

\section{Recommended Citation}

Ayela, Cedric; Heinrich, Stephen M.; Josse, Fabien; and Dufour, Isabelle, "Resonant Microcantilevers for the Determination of the Loss Modulus of Thin Polymer Films" (2011). Civil and Environmental

Engineering Faculty Research and Publications. 68.

https://epublications.marquette.edu/civengin_fac/68 


\title{
Resonant Microcantilevers for the Determination of the Loss Modulus of Thin Polymer Films
}

\author{
Cedric Ayela
}

Laboratoire de I'Intégration du Matériau au Système, Université de Bordeaux, Talence, France

Stephen M. Heinrich Department of Civil and Environmental Engineering, Marquette University Milwaukee, Wisconsin

Fabien Jose

Department of Electrical and Computer Engineering, Marquette University Milwaukee, Wisconsin

\section{Isabelle Dufour}

Laboratoire de l'Intégration du Matériau au Système, Université de Bordeaux, Talence, France

\footnotetext{
Abstract: The increasing interest in polymer materials creates the need for accurate tools to characterize their mechanical properties. Due to energy dissipation in polymers during deformation, these materials exhibit viscoelastic behavior. Accurate determination of these viscoelastic properties

[Journal of Microelectromechanical Systems, Vol 20, No. 4 (August 2011): pg. 788-790. DOI. This article is @ Institute of Electrical and Electronics Engineers (IEEE) and permission has been granted for this version to appear in $\underline{\mathrm{e}}-$ Publications@Marquette. Institute of Electrical and Electronics Engineers (IEEE) does not grant permission for this article to be further copied/distributed or hosted elsewhere without the express permission from Institute of Electrical and Electronics Engineers (IEEE).]
} 
and, more specifically, viscous losses, remains challenging and mainly unknown for thin polymer films. In this paper, a straightforward method to determine the loss modulus of organic materials using resonating microcantilevers has been developed. The extracted results for polyisobutylene show the variation of viscous losses over a large range of frequencies $(7-350 \mathrm{kHz})$.

Progress in polymer chemistry allows the synthesis of materials with specific properties depending on the application. Indeed, increasing interest in polymers as sensitive coatings for biochemical sensing in both gas and liquid phases is found in the literature, and more specifically when associated with microsystems. Properties such as selectivity, binding capacity, and reversibility are often ensured by organic materials for these applications. Another example concerns polymers as structural layers for microelectromechanical systems applications. In this case, low stiffness is the main required characteristic. For the optimal use of polymers, the characterization of their intrinsic mechanical properties is of particular importance. A direct consequence of incomplete characterization is an inaccurate correlation between theory and experiment on the behavior of microstructures. One major cause of this miscorrelation is the neglected energy dissipation that occurs during deformation due to the material's viscoelasticity. To account for this, polymer materials may be characterized mechanically by using a complex Young's modulus, where the real part corresponds to elastic stiffness and the imaginary part corresponds to energy dissipation. Moreover, each part is frequency dependent, making their determination challenging. As a consequence, the database of mechanically characterized viscoelastic materials is restricted to conventional ones, such as polyisobutylene (PIB) or poly(methylmethacrylate), whose properties are usually determined via experimentation on bulk materials. In this context, a simple and reliable method to determine the viscoelastic properties of polymeric thin films over a large frequency range is of major interest.

In this paper, polymer-coated silicon microcantilevers vibrating in different resonance modes are used for the determination of viscoelastic properties of PIB thin films. More specifically, values of the imaginary part of the complex modulus were obtained, as these values are often ignored due to lack of data, despite the fact that they are needed in many important applications to accurately quantify the energy dissipation that occurs in such materials.

With this aim in mind, an analytical model has been developed for calculating the resonant frequency of the out-of-plane flexural mode and the quality factor due to viscoelastic losses in the coating on

[Journal of Microelectromechanical Systems, Vol 20, No. 4 (August 2011): pg. 788-790. DOI. This article is @ Institute of Electrical and Electronics Engineers (IEEE) and permission has been granted for this version to appear in ePublications@Marquette. Institute of Electrical and Electronics Engineers (IEEE) does not grant permission for this article to be further copied/distributed or hosted elsewhere without the express permission from Institute of Electrical and Electronics Engineers (IEEE).] 
an elastic cantilever. In this paper, we utilize a straightforward extension of the work in to calculate the resonant frequency and quality factor of the nth out-of-plane flexural mode. The following notation is used: $L, b, h_{1}, E_{1}$, and $\rho_{1}$ are the length, width, thickness, elastic Young's modulus, and density of the microcantilever's base material, respectively, and $h_{2}, E^{\prime}{ }_{2}+\mathrm{jE}^{\prime \prime}{ }_{2}$, and $\rho 2$ are the thickness, complex Young's modulus, and density of the viscoelastic coating that is assumed to cover one of the two larger faces of the cantilever. In the case of a silicon cantilever with polymeric coating, because of the large difference in the values of Young's moduli, the following approximate equations have been used to calculate the resonant frequency and quality factor associated with viscoelastic losses in the coating of the $n$th mode:

$$
\begin{aligned}
f_{n} & =\frac{\lambda_{n}^{2} h_{1}}{2 \pi L^{2}} \sqrt{\frac{E_{1}}{12 \rho_{1}} \frac{1+\frac{E_{2, n}^{\prime}}{2 E_{1} h_{1}^{3}}\left[h_{2}^{3}+3 h_{2}\left(h_{1}+h_{2}\right)^{2}\right]}{\sqrt{1+\frac{\rho_{2} h_{2}}{\rho_{1} h_{1}}}}} \\
Q_{n \_v e}= & \frac{E_{1} h_{1}^{3}}{E_{2, n}^{\prime \prime}\left[h_{2}^{3}+3 h_{2}\left(h_{1}+h_{2}\right)^{2}\right]}
\end{aligned}
$$

$\lambda_{1}=1.875, \lambda_{2}=4.694, \lambda_{3}=7.855$, and $\lambda_{4}=10.996$.

Note that the " $n$ " subscript appears on the coating moduli because they are dependent on frequency, i.e., on the particular mode of vibration. In the case of $(2)$, the frequency dependence of the coating loss modulus within the 3-dB bandwidth of each resonant peak has been neglected. Due to the fact that the ratio $\rho_{2} / \rho_{1}$ is much larger than $E_{2}^{\prime} / E_{1}$ for polymeric coatings on silicon (values for $E_{2}^{\prime}$ are between 4.7 and $148 \mathrm{MPa}$ in the frequency range that is considered ), the resonant frequency formula (1) may be simplified and expressed as a function of the resonant frequency of the uncoated cantilever $f_{n, 0}$

$$
\begin{gathered}
f_{n}=\frac{f_{n, 0}}{\sqrt{1+\frac{\rho_{2} h_{2}}{\rho_{1} h_{1}}}} \\
f_{n, 0}=\frac{\lambda_{n}^{2} h_{1}}{2 \pi L^{2}} \sqrt{\frac{E_{1}}{12 \rho_{1}}}
\end{gathered}
$$

The total quality factor $Q_{n}$ depends on the quality factor of the cantilever without the coating $\mathrm{Q}_{n, 0}$ (viscous losses in the surrounding medium, internal losses, support losses, etc.) and the quality factor associated with the viscoelastic losses in the coating $Q_{\text {n_ve }}$ as follows:

[Journal of Microelectromechanical Systems, Vol 20, No. 4 (August 2011): pg. 788-790. DOI. This article is @ Institute of Electrical and Electronics Engineers (IEEE) and permission has been granted for this version to appear in $\underline{\text { e- }}$ Publications@Marquette. Institute of Electrical and Electronics Engineers (IEEE) does not grant permission for this article to be further copied/distributed or hosted elsewhere without the express permission from Institute of Electrical and Electronics Engineers (IEEE).] 
NOT THE PUBLISHED VERSION; this is the author's final, peer-reviewed manuscript. The published version may be accessed by following the link in the citation at the bottom of the page.

$$
\begin{aligned}
& Q_{n}=\quad \frac{Q_{n, 0} Q_{n \_v e}}{Q_{n, 0}+Q_{n \_v e}} \\
& =\quad Q_{n, 0}\left(1-\frac{Q_{n, 0}}{1+\frac{Q_{n, 0}}{Q_{n \_v e}}} \frac{E_{2, n}^{\prime \prime}\left[h_{2}^{3}+3 h_{2}\left(h_{1}+h_{2}\right)^{2}\right]}{E_{1} h_{1}^{3}}\right) .
\end{aligned}
$$

According to (3), the coating stiffness has a negligible effect on frequency compared to the coating mass. When this case applies (e.g., polymers on silicon), the shift in resonant frequency due to the coating permits the determination of coating thickness when the coating density is known. Rearranging (5), the measurement of the quality factor with and without the coating permits the calculation of the loss modulus of the coating

$$
\frac{E_{2, n}^{\prime \prime}}{E_{1}}=\frac{1}{\beta^{3}+3 \beta(1+\beta)^{2}} \frac{Q_{n, 0}-Q_{n}}{Q_{n, 0} Q_{n}}, \beta \equiv \frac{h_{2}}{h_{1}} .
$$

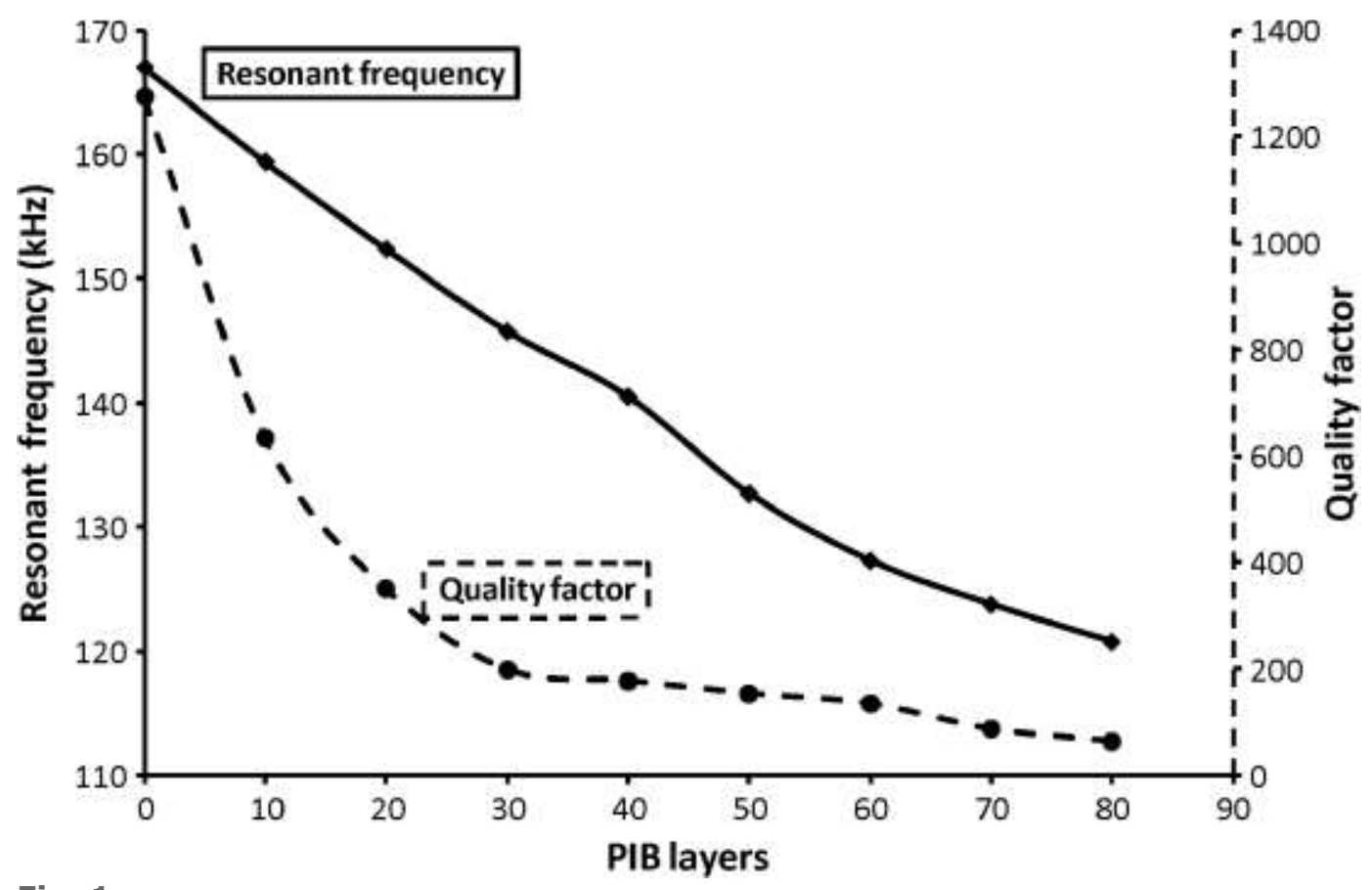

Fig. 1.

Evolution of both the resonant frequency and total quality factor after successive PIB layer depositions (third flexural mode of cantilever 1 ).

Electrical and Electronics Engineers (IEEE) and permission has been granted for this version to appear in ePublications@Marquette. Institute of Electrical and Electronics Engineers (IEEE) does not grant permission for this article to be further copied/distributed or hosted elsewhere without the express permission from Institute of Electrical and Electronics Engineers (IEEE).] 
NOT THE PUBLISHED VERSION; this is the author's final, peer-reviewed manuscript. The published version may be accessed by following the link in the citation at the bottom of the page.

To experimentally determine the viscoelastic properties of thin polymer films over a large frequency range, a set of three silicon microcantilevers was used. Cantilevers 1, 2, and 3 were characterized by lengths, widths, and thicknesses

of $2000 \times 200 \times 27 \mu^{3}, 3000 \times 200 \times 21 \mu^{3}$, and $3000 \times 200 \times 57 \mu^{3}$, respectively. Integrated actuation of the structures was achieved by electromagnetic actuation, while their frequency response was measured using a laser Doppler optical vibrometer (Polytec MSA-500). The fabrication process and actuation principle are detailed in [7].

First, uncoated cantilevers were characterized to obtain the resonant frequency and quality factor of the first four transverse flexural modes, defining the overall frequency range. With the three geometries, a frequency range of $7-354 \mathrm{kHz}$ was spanned. Dynamic characterization of uncoated cantilevers allowed the determination of the cantilever thickness from the resonant frequency measurement $f_{n, 0}$ and (4). Quality factor measurement resulted in the determination of $Q_{n, 0}$, which is necessary to use (6) for the loss modulus estimation.

PIB (Sigma-Aldrich) was next deposited on the silicon cantilevers using a spray-coating technique. The PIB was dissolved in low vapor pressure chloroform permitting layer-by-layer coating. As a result, successive PIB layers were deposited onto the cantilevers with a $130-170-\mathrm{nm}$ per-layer thickness for a 2 -s spraying time. A solvent evaporation step was performed after each deposition, ensuring that no residual solvent traces remained in the PIB layer. Following deposition, resonant frequency $f_{n}$ and quality factor $Q_{n}$ for each mode were measured for the three cantilevers when ten PIB layers were applied, and the sequence was repeated for up to 80 layers. Fig. 1 shows the evolution of resonant frequency and total quality factor of the third flexural mode on cantilever 1 , after successive deposition of PIB layers. For the quality factor, a strong decrease is observed for the first 30 layers coated, while a lower influence occurs when a quality factor close to 100 is measured, a result that is consistent with that predicted by (5).

Experimental data for the four out-of-plane flexural modes of the three cantilevers have been collected. Using the measured resonant frequency $f_{n}$ and $(3)$, values of $h_{2}$ corresponding to the successively deposited PIB layers were obtained, while the measured quality factor $Q_{n}$ permitted the calculation of the loss modulus of PIB at various frequencies via (6). An averaged value of the frequencydependent loss modulus is obtained for different coating thicknesses

[Journal of Microelectromechanical Systems, Vol 20, No. 4 (August 2011): pg. 788-790. DOI. This article is @ Institute of Electrical and Electronics Engineers (IEEE) and permission has been granted for this version to appear in ePublications@Marquette. Institute of Electrical and Electronics Engineers (IEEE) does not grant permission for this article to be further copied/distributed or hosted elsewhere without the express permission from Institute of Electrical and Electronics Engineers (IEEE).] 
(with $\beta<0.4$ ) and plotted in Fig. 2, where error bars represent the values obtained for these different thicknesses.

From this figure, the frequency dependence of $E^{\prime \prime}{ }_{2}$ is exhibited over a large frequency range, from 7 to $354 \mathrm{kHz}$. A comparable behavior was obtained for the three cantilevers, allowing the fitting of the experimental data using a power-law curve. Values of $\mathrm{E}^{\prime \prime}{ }_{2}$ for PIB ranged from 6.5 to $219 \mathrm{MPa}$, showing the large range of values achievable with the method. These values of $E^{\prime \prime} 2$ are low compared to the Young's modulus of silicon $E_{1}$, which validates the assumption implicit in (2) and (3).

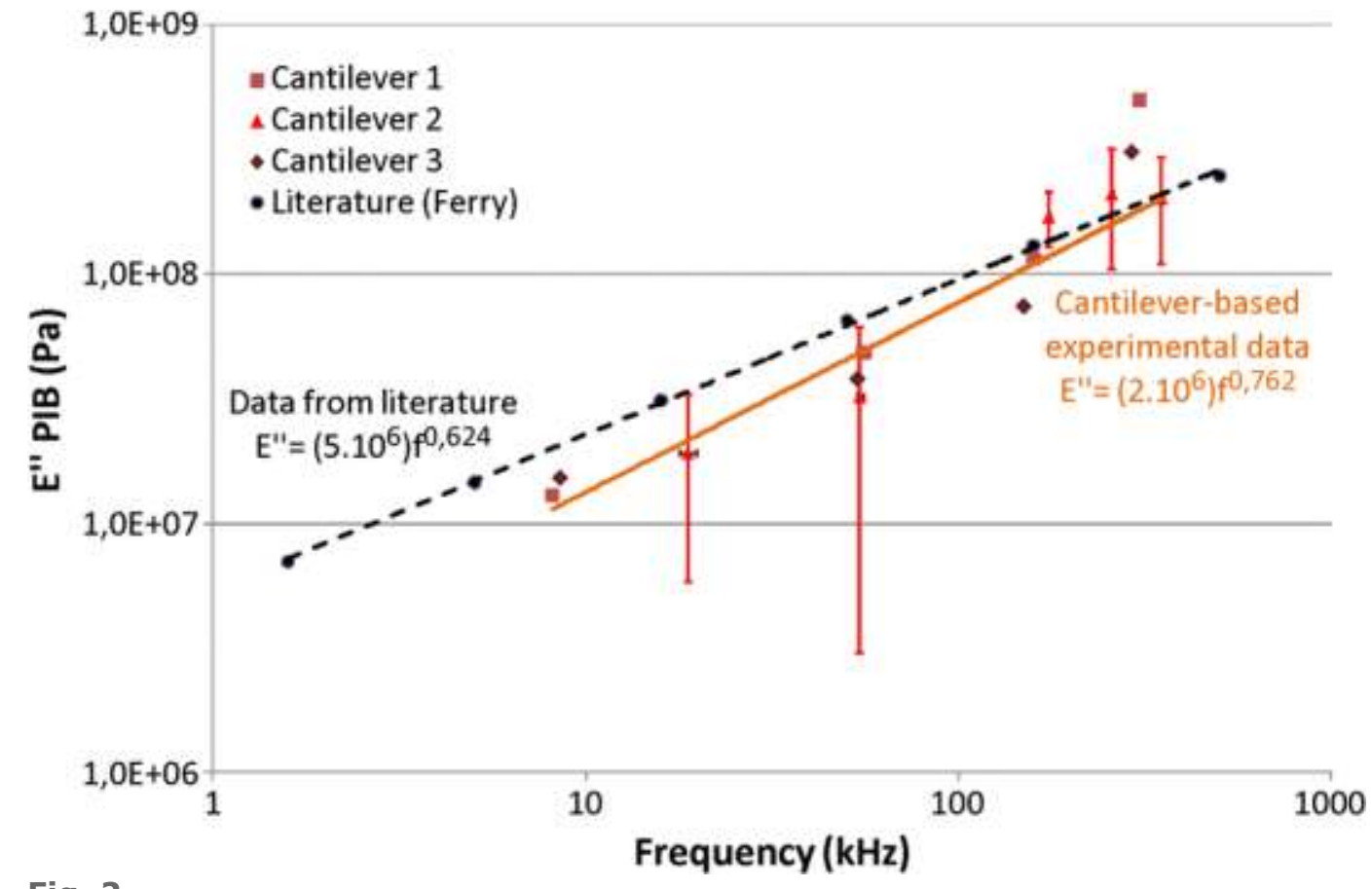

Fig. 2.

Frequency-dependent loss modulus of PIB (log scale).

Also shown in Fig. 2 are data corresponding to Ferry's bulk PIB data, where the values of $E^{\prime \prime}$ are obtained from Ferry's complex shear modulus values by assuming a constant value of Poisson's ratio of 0.49 [5]. Compared with the values obtained in this paper, there is a similar frequency-dependent trend, while the magnitudes of the $\mathrm{E}^{\prime \prime}{ }_{2}$ are comparable. The differences in the results are attributable to several sources, including the following: 1) Losses associated with Si-PIB interfacial phenomena, which are expected to become more important for smaller coating thicknesses, are reflected in the $E^{\prime \prime} 2$ measurements of the proposed method; 2) viscous losses in the surrounding fluid are assumed to be unaffected by the coating

[Journal of Microelectromechanical Systems, Vol 20, No. 4 (August 2011): pg. 788-790. DOI. This article is () Institute of Electrical and Electronics Engineers (IEEE) and permission has been granted for this version to appear in $\underline{\mathrm{e}}-$ Publications@Marquette. Institute of Electrical and Electronics Engineers (IEEE) does not grant permission for this article to be further copied/distributed or hosted elsewhere without the express permission from Institute of Electrical and Electronics Engineers (IEEE).] 
thickness; and 3) differences in bulk properties and thin-coating properties of polymers are regularly observed due to the arrangement of polymer chains at the microscale differing from those at the macroscale [8], [9]. This difference also depends on the method used for deposition.

To summarize, a new simple method has been proposed for the determination of the loss modulus in soft viscoelastic materials such as polymers. We believe that such a method can enhance the knowledge base on thin polymer films. Moreover, the method can provide a lowcost means of obtaining properties on a wide variety of materials and may be useful in quantifying the effects of both frequency and thickness on the loss modulus of thin layers of viscoelastic materials.

\section{References}

F. Lochon, I. Dufour, D. Rebire, "An alternative solution to improve sensitivity of resonant microcantilever chemical sensors: Comparison between using high-order modes and reducing dimensions", Sens. Actuators B Chem., vol. 108, no. 1/2, pp. 979-985, Jul. 2005.

J. Hossenlopp, L. Jiang, R. W. Cernosek, F. Josse, "Characterization of epoxy resin (SU-8) film using thickness-shear mode (TSM) resonator under various conditions", J. Polym. Sci. B Polym. Phys., vol. 42, no. 12, pp. 2373-2384, Jun. 2004.

A. Johansson, G. Blagoi, A. Boisen, "Polymeric cantilever-based biosensors with integrated readout", Appl. Phys. Lett., vol. 89, no. 17, pp. 173505, Oct. 2006.

A. Greve, S. Keller, A. L. Vig, A. Kristensen, D. Larsson, K. Yvind, J. M. Hvam, M. Cerruti, A. Majumdar, A. Boisen, "Thermoplastic microcantilevers fabricated by nanoimprint lithography", $J$. Micromech. Microeng., vol. 20, no. 1, pp. 015009, Jan. 2010.

J. D. Ferry, Viscoelastic Properties of Polymers, New York:Wiley, 1961.

[Journal of Microelectromechanical Systems, Vol 20, No. 4 (August 2011): pg. 788-790. DOI. This article is @ Institute of Electrical and Electronics Engineers (IEEE) and permission has been granted for this version to appear in ePublications@Marquette. Institute of Electrical and Electronics Engineers (IEEE) does not grant permission for this article to be further copied/distributed or hosted elsewhere without the express permission from Institute of Electrical and Electronics Engineers (IEEE).] 
NOT THE PUBLISHED VERSION; this is the author's final, peer-reviewed manuscript. The published version may be accessed by following the link in the citation at the bottom of the page.

I. Dufour, F. Lochon, S. Heinrich, F. Josse, D. Rebire, "Effect of coating viscoelasticity on quality factor and limit of detection of microcantilever chemical sensors", IEEE Sensors J., vol. 7, no. 2, pp. 230-236, Feb. 2007.

L. Fadel, F. Lochon, I. Dufour, O. Franais, "Chemical sensing: Millimeter size resonant microcantilever performance", $\mathrm{J}$. Micromech. Microeng., vol. 14, no. 9, pp. S23-S30, Aug. 2004.

G. Luengo, F.-J. Schmitt, R. Hill, J. Israelachvili, "Thin film rheology and tribology of confined polymer melts: Contrasts with bulk properties", Macromolecules, vol. 30, no. 8, pp. 2482-2494, Apr. 1997.

K. Tawa, W. Knoll, "Out-of-plane photoreorientation of azo dyes in polymer thin films studied by surface plasmon resonance spectroscopy", Macromolecules, vol. 35, no. 18, pp. 7018-7023, Jul. 2002.

[Journal of Microelectromechanical Systems, Vol 20, No. 4 (August 2011): pg. 788-790. DOI. This article is (C) Institute of Electrical and Electronics Engineers (IEEE) and permission has been granted for this version to appear in ePublications@Marquette. Institute of Electrical and Electronics Engineers (IEEE) does not grant permission for this article to be further copied/distributed or hosted elsewhere without the express permission from Institute of Electrical and Electronics Engineers (IEEE).] 